Article

\title{
Sustainable Extraction and Use of Natural Bioactive Compounds from the Waste Management Process of Castanea spp. Bud-Derivatives: The FINNOVER Project
}

\author{
Dario Donno ${ }^{1,2, *(\mathbb{D}}$, Federica Turrini ${ }^{3}{ }^{(\mathbb{C}}$, Raffaella Boggia ${ }^{3} \mathbb{D}$, Maddalena Guido ${ }^{4}$, \\ Giovanni Gamba ${ }^{1,2}$, Maria Gabriella Mellano ${ }^{1,2}$, Isidoro Riondato ${ }^{1}$ and Gabriele L. Beccaro ${ }^{1,2}$ \\ 1 Department of Agriculture, Forestry and Food Science-DISAFA, University of Torino, 10095 Grugliasco, \\ Italy; giovanni.gamba@unito.it (G.G.); gabriella.mellano@unito.it (M.G.M.); isidoro.riondato@unito.it (I.R.); \\ gabriele.beccaro@unito.it (G.L.B.) \\ 2 Chestnut R\&D Center, 12013 Chiusa di Pesio, Italy \\ 3 Department of Pharmacy_DIFAR, University of Genoa, 16148 Genova, Italy; turrini@difar.unige.it (F.T.); \\ boggia@difar.unige.it (R.B.) \\ 4 Azienda Agricola Geal Pharma, 10060 Bricherasio, Italy; info@gealpharma.it \\ * Correspondence: dario.donno@unito.it; Tel.: +39-011-670-8751
}

Received: 17 November 2020; Accepted: 16 December 2020; Published: 19 December 2020

check for updates

\begin{abstract}
The FINNOVER project provides a technical and economic path for the creation of new supply chains, or their development, for the sustainable extraction and utilization of natural biologically active molecules. In this research, a green extraction method and re-use strategy of botanical by-products are developed and used to obtain value-added products as an ecological alternative to waste composting or incineration. It was applied to the production of Castanea spp. bud-derivatives (a specific category of food supplements derived from plant material) and their by-products. This study aimed to compare the phytochemical composition of Castanea spp. bud-preparations (herbal preparations from buds and sprouts) with the extracts derived from the bud-waste management process. Bioactive compounds were extracted by maceration in hydroglyceroalcoholic solution (traditional method) and by a green extraction technique (Pulsed Ultrasound-Assisted Extraction-PUAE) and identified and quantified by HPLC methods obtaining a specific chromatographic profile. PUAE extracted a total content of $160.42 \mathrm{mg} / 100 \mathrm{~g} \mathrm{FW}$, a good amount if compared to the relative commercial product $(1276.17 \mathrm{mg} / 100 \mathrm{~g} F W)$. About $13 \%$ of the chemical content of Castanea spp. bud-preparations was maintained in the by-product extracts. This research showed that PUAE may be considered as a sustainable alternative to waste management based on incineration or composting. This study could be considered by the industries for the development of new products for the market derived from the bud-derivative processing waste.
\end{abstract}

Keywords: chestnut; bud-preparations; processing waste; eco-sustainable extraction; botanicals

\section{Introduction}

In the last years, innovative strategies for re-use and valorization of food waste are becoming more and more used in the food and pharmaceutical industry if compared to the conventional waste processing techniques, as composting or incineration, and they are usually called as " 2 nd generation food waste management" [1]. These strategies are very important for the agri-food commercial companies, but there are also small-scale industries, as companies producing herbal preparations or 
food supplements, that may apply them to convert their production waste to a high-quality source of bioactive compounds (botanicals) to be valorized [2].

Complementary medicine has recently attracted the attention of physicians and medical professionals. Moreover, commercial products derived from plant material (as herbal preparations) are now widely appreciated by consumers and available on the market. In particular, bud-derivatives (or bud-preparations) represent a new type of natural products derived from plants, that may be classified as food supplements or homoeopathic medicines depending on national regulatory and company policies. Their production starts from fresh meristematic plant tissues that are macerated in a mixture of different solvents (glycerol, ethanol, and water) [3,4].

Even if bud-preparations are products widely used in European countries, they are still poorly studied until today. Herbal preparations derived from buds and young sprouts show many different biologically active molecules (botanicals). Many bioactive compounds with several therapeutic properties (e.g., terpenes, alkaloids, enzymes, glycosides, amino acids, phenolic compounds, anthraquinones, and coumarins) have been isolated and identified in many common botanical species [5]. In addition to these substances, other biomolecules have been quantified in plants and derived herbal preparations, as macro- and microelements, vitamins, organic acids, and other nutritional substances with health-promoting effects in humans, whose concentration may be influenced by genetic, agronomic, and environmental conditions together to manufacturing factors [3]. Familiar producers and commercial companies present their natural products by highlighting their higher health-promoting properties and economic convenience in relation to other similar products on the market [6]. Despite the increasing interest in these products, studies on these plant derivatives are still limited or absent. In particular, thanks to their specific phytochemical composition and health-promoting properties (positive effects against cardiovascular diseases and cystitis, and on vascular circulation), buds, bark, and leaves of Castanea spp. are traditionally used as raw material for herbal companies [7], but no systematic phytochemical studies have been performed on the presence of significant amounts of biologically active molecules [8].

Bud-derivative production is quite expensive in relation to other herbal extracts because the availability of plant material (buds or young sprouts) is so much limited during the collecting period (late winter-early spring). For this reason, the sustainable valorization of their by-products may have an important economic impact and an innovative influence on the producers and herbal companies. The utilization of eco-sustainable extractions could become very important to extract bioactive molecules from herbal derivative production waste. Ultrasounds have recently emerged among green technologies due to the advantages shown in the several processing steps (e.g., cutting, degassing, filtration), preservation (e.g., inactivation of microorganism and enzyme), and extraction of a natural preparation [9]. In particular, ultrasound-assisted-extraction (UAE) is a relatively low-cost, green-effective, efficient, and sustainable methodology [1,10], that show many positive traits in relation to traditional extraction systems [11] as shown in Figure 1. If the UAE is pulsed-mode utilized (PUAE), the ultrasound processor is intermittently turned on and off during the experiments. This technical modification is useful to preserve the thermolabile compounds from degradation because a lower heat is generated in comparison with a continuous sonication [12].

FINNOVER (Innovative strategies for the development of cross border green supply chains) is an Italy/France Interreg ALCOTRA cross-border (action period: 2017-2020) project started for the innovation and sustainable implementation of agro-industrial production chains according to the green circular economy, in particular regarding the management of agricultural and food processing waste. This project supports the valorization of eco-sustainable and innovative production of botanical products derived from natural resources and industry by-products to sustainably exploit the agrobiodiversity widespread in the ALCOTRA territory. Bud-preparations, a recent category of natural products marketed in the European Union as food supplements derived from plants (Directive 2002/46/EC of the European Parliament), are one of the main productions considered in the FINNOVER project [13]. This research showed new sustainable trends in the supply chain to produce herbal preparations and food 
supplements derived by Castanea spp. buds. This topic is of increasing interest because the valorization of food organic waste is one of the most important current research areas. This study aimed at the evaluation of a pulsed ultrasound-assisted-extraction method as an effective tool for the valorization and sustainable management of processing waste derived from the production of traditional herbal preparations from chestnut buds (Castanea spp. bud-preparations). This study proposed a specific re-use strategy to convert processing waste to a new source of bioactive compounds by a sustainable extraction. In this research pulsed ultrasound-assisted extraction was not proposed as an alternative to maceration for the extraction of bioactive compounds, but it was intended as a tool to extract further biomolecules from processing waste; then, these substances may be used in new health-promoting products (e.g., cosmetic products). The results of this study could be considered by the industries for the development of new products for the market derived from the bud-derivative processing waste.

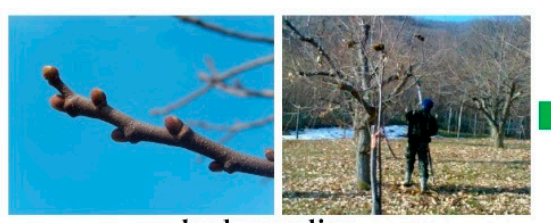

bud-sampling

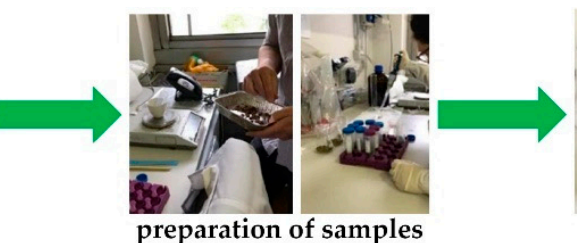

preparation of samples

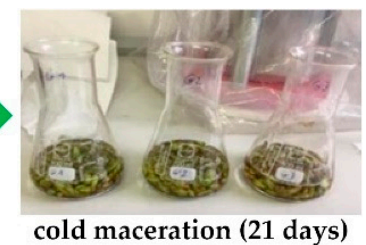

cold maceration (21 days)
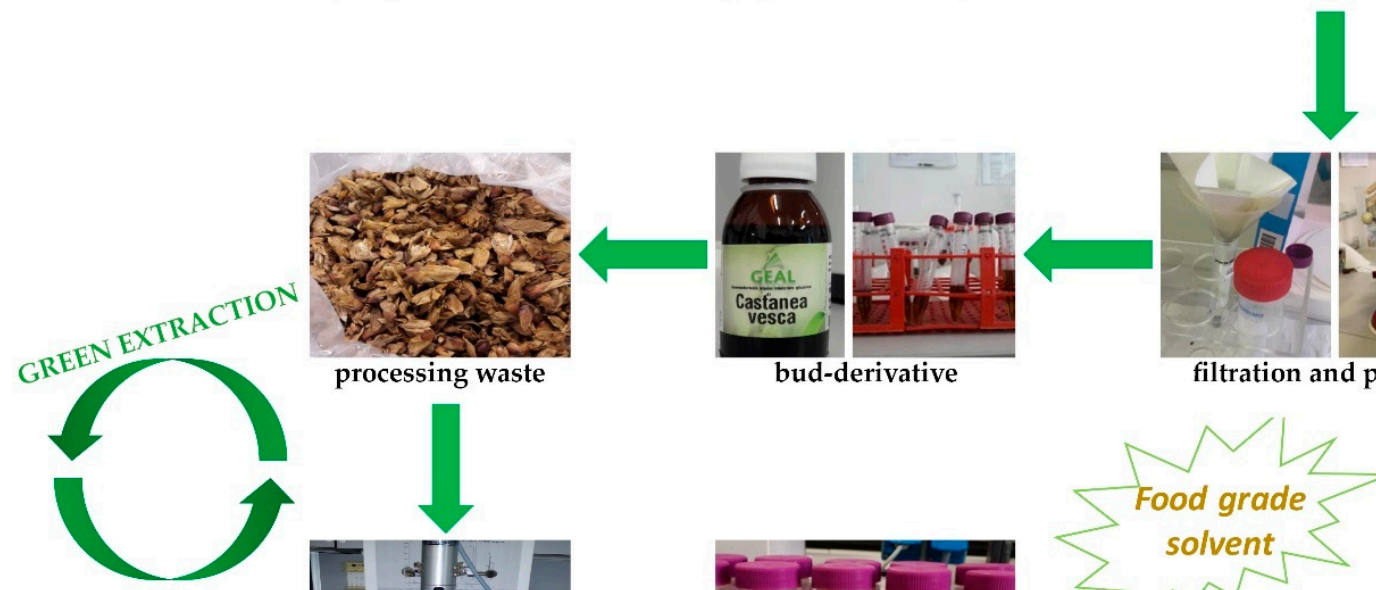

bud-derivative

processing waste

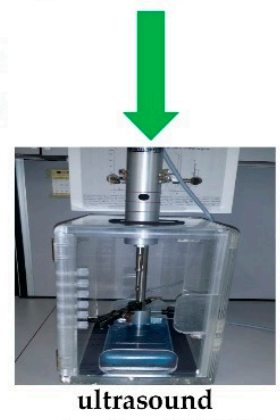

extraction (PUAE)

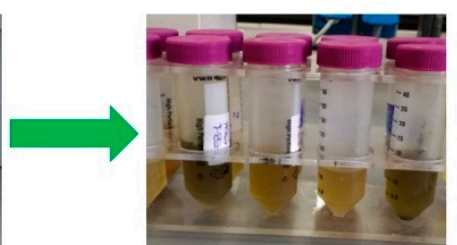

PUAE extracts

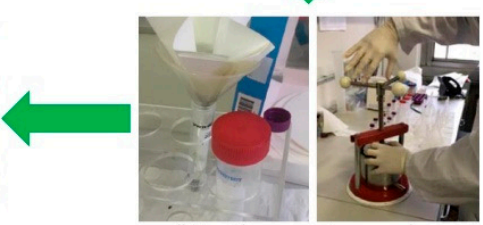

filtration and pressing

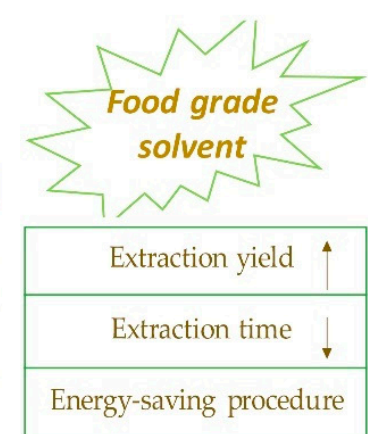

Figure 1. Bud-sampling and preparation of commercial bud-derivatives and PUAE extracts. The advantages of ultrasound-assisted extraction in relation to traditional extraction systems were reported closed to PUAE extracts.

\section{Materials and Methods}

\subsection{Plant Material}

Buds were collected from Castanea spp. spontaneous plants in the Pellice, Chisone, Bronda, Varaita, and Germanasca valleys (Turin Province, Italy) during early spring (March 2018). The fresh raw material was used by Geal Pharma (Bricherasio, Turin, Italy), an Italian commercial company, to formulate the relative bud-preparations following the procedure detailed in the French Pharmacopeia [14]. The processing waste derived from the bud-derivative production was utilized for the green extraction by PUAE. 


\subsection{Preparation of Commercial Bud-Derivatives}

The extraction process was performed following the information reported by the 'Homeopathic preparations' monograph, quoted in the French Pharmacopoeia (8th edition, 1965) [14]. The bud-derivatives were prepared using one part of the plant material (intended as dried weight) in 20 parts of hydroglyceroalcoholic solution. Molecules were extracted by cold maceration for 21 days, in a solution of glycerol and ethanol:water $(95: 5 v / v)$, followed by a first filtration (Whatman filter paper, hardened ashless circles, $185 \mathrm{~mm}$ diameter), a manual pressing and, after decanting for 2 days, a second filtration. Macerates were stored in dark bottles at normal atmosphere (N.A.), $4{ }^{\circ} \mathrm{C}$, and $95 \%$ relative humidity (R.H.) until analysis. At the same time, the solid by-products (processing waste of bud-derivative production), obtained after the 2 nd filtration, were stored at $-20^{\circ} \mathrm{C}$ until PUAE process.

\subsection{Management of Processing Waste by Pulsed Ultrasound-Assisted Extraction (PUAE)}

The frozen waste material was ground and homogenized in an automatic blender (Grindomix GM200, Retsch, Haan, Germany) at $5000 \mathrm{rpm}(20 \mathrm{~s})$ and then sieved (150 $\mu \mathrm{m}$ mesh size). The content of moisture presented a value of about $52.0 \%$ obtained by a MA Moisture Sartorius analyzer (Goettingen, Germany). All the measures were carried out in triplicate and mean values ( \pm standard deviations) were reported as results.

The processing waste extraction was directly performed in a pulsed manner at a temperature maintained below $70 \pm 1{ }^{\circ} \mathrm{C}$. The same solvent utilized in the traditional method to produce commercial preparations was used as the extraction solvent. PUAE was carried out by a sonicator (Hielscher Ultrasonics UP200 St, Teltow, Germany) equipped with titanium (7 mm i.d.) sonotrode useful for the utilized volumes of extraction solution; the sonicator presented an effective output of $200 \mathrm{~W}$ and a frequency of $26 \mathrm{kHz}$ [15]. The pulse interval and pulse duration referred to "OFF" time and "ON" time of the sonochemical reactor, respectively. The cycle time was represented by the sum of the total time of a pulse duration period and a pulse interval period. The duty cycle (related to a second in $0.1 \mathrm{~s}$ steps and expressed as \%) was the proportion of the pulse duration period in relation to the cycle time.

The PUAE process conditions have been optimized by a factorial design $\left(2^{4-1}\right.$ fractional). Four extraction process variables were studied; in particular, (i) the duty cycle $(20 \%, 50 \%, 80 \%)$; (ii) the extraction time ( $5 \mathrm{~min}, 10 \mathrm{~min}, 15 \mathrm{~min}$ ); (iii) the amplitude level (30\%, 40\%, 50\%); (iv) the sample/solvent ratio, at two different levels (first step: 1/40, 1/50, 1/60; second step: 1/20, 1/15 and 1/10). Moreover, commercial bud-derivatives produced by Geal Pharma company using the same plant material, whose by-products were studied, were also analyzed at two different dilutions (commercial product_d80 was diluted 1:80 and commercial product_d100 was diluted 1:100).

\subsection{UV-Vis Spectroscopy}

The extracts were centrifuged for $10 \mathrm{~min}$ at $3500 \mathrm{rpm}$ after an under-vacuum filtration by filter paper (Macherey-Nagel MN 615, 70 mm, Düren, Germany) and then diluted using a water/ethanol/glycerol solution (50:20:30, v:v:v).

Samples were analyzed by an Agilent 8453 spectrophotometer (Waldbronn, Germany) with $1 \mathrm{~nm}$ resolution at room temperature, recording all the UV-Vis spectra in a $230-500 \mathrm{~nm}$ range $(1 \mathrm{~cm}$ path-length quartz cuvettes were used). The total spectrum of all the analyzed samples was recorded three times $(\mathrm{N}=3)$, against the blank standard, and then the mean values were considered as results.

\subsection{HPLC Sample Preparation and Chromatographic Analysis}

PUAE extracts and bud-derivatives were stored for a few days at N.A., $4{ }^{\circ} \mathrm{C}$ and $95 \%$ R.H. after filtration with $0.45 \mu \mathrm{m}$ pre-injection filters (polytetrafluoroethylene membrane, PTFE). All the extracts were analyzed without dilution. For analysis of vitamin C, $750 \mu \mathrm{L}$ of extracted samples were mixed with $250 \mu \mathrm{L}$ of o-phenylenediamine (OPDA) solution $\left(18.8 \mathrm{mmol} \mathrm{L}^{-1}\right)$ for dehydroascorbic 
acid derivatization into the fluorophore 3-(1,2-dihydroxy ethyl)furo(3,4-b)quinoxaline-1-one (DFQ). The derivatized extracts were analyzed after $37 \mathrm{~min}$ in the dark.

The analysis was performed by an Agilent 1200 HPLC-UV-Vis Diode Array Detector (Agilent Technologies, Santa Clara, CA, USA). Molecules were separated on a Kinetex C18 column $(4.6 \times 150 \mathrm{~mm}$, $5 \mu \mathrm{m}$, Phenomenex, Torrance, CA, USA). Chromatographic conditions were reported in Supplementary Table S1 following the methods previously described and validated by Donno et al. [16].

Several bioactive substances were used as biomarkers for the evaluation of phytocomplex, both for PUAE extracts and commercial bud-preparations. Phytocomplex was defined as the sum of biomolecules with proved health-promoting properties and characterized by a comparison of spectroscopic data and retention times with standards analyzed in the same analytical conditions. Quantitative determinations in bud-preparations and PUAE extracts were carried out by an external standard method with calibration curves with good linearity for a four-point plot [peak area (y) versus the concentration (x)]. The phytochemical composition was evaluated by the "multi-marker approach" by Mok and Chau [17]. The approach utilized in this study is the natural extension of the "marker approach" (i.e., measuring the concentration of one or very few biomarkers or biologically active molecules) because it uses many specific components to represent the chemical profile of the whole sample [18-20]. In this research, five phenolic classes (15 biomarkers) were selected for the phytochemical composition evaluation. Levels of vitamin C ( 2 markers) and organic acids (6 markers) were investigated as well. Biomolecule contents were expressed as $\mathrm{mg} / 100 \mathrm{~g}$ of fresh weight (FW).

\subsection{Statistical Analysis}

Student's t-test was used to define significant differences in the phytochemical composition between PUAE extracts and commercial bud-derivatives. Differences with $p<0.05(\mathrm{~N}=3)$ were considered statistically significant and highlighted with different letters in the results.

\section{Results and Discussion}

\subsection{Extraction Optimization}

Several studies highlighted the efficiency of green technologies for the extraction of bioactive substances from processing waste generated by food and herbal industry. Their effectiveness is very variable due to process parameters (e.g., temperature, pressure, solvent type, time) and sample characteristics (e.g., physical structure and chemical composition). Promising and innovative extraction techniques were recently used (e.g., ultrasound-assisted extraction) to maximize the recovery of large amounts of bioactive molecules from by-products derived by herbal preparation production in a shorter time. In particular, the Pulsed Ultrasound-Assisted Extraction, if compared to conventional extraction (e.g., maceration), provides a good extraction efficiency according to two important physical phenomena, as the diffusion across the plant cell wall and the flushing of the cell contents after the wall breaking [21].

In this study eleven extracts (identified as CA from 01 to 11), in accordance with the experimental plan (step 1), were prepared and spectrophotometrically analyzed together with two diluted commercial products (reported as comm_d80 and comm_d100). Figure 2A shows that the CA08 extract was the most suitable experimental condition for the aim of this research. Indeed, this PUAE extract provided the most similar spectrum to the Geal Pharma commercial preparations (comm_d80 and comm_d100). For this reason, this condition was selected as the best one and it was further optimized in step 2. UAE can be performed in a continuous or pulsed mode depending on how the irradiation is carried out. Several studies reported that a prolonged treatment in a continuous manner should be not used, because it may cause the oxidation and/or degradation of the bioactive compounds due to the generation of highly reactive hydroxyl radicals by high powers $(750 \mathrm{~W})$ or high frequencies (358 and $850 \mathrm{kHz})$. Moreover, several studies are carried out with low-frequency equipment $(20-60 \mathrm{kHz})$ 
because these frequencies should not influence the stability of biomolecules (e.g., phenolics) after the extraction [22]. For this reason, these conditions were performed in this study.

\begin{tabular}{ccccc}
$\begin{array}{c}\text { A } \\
\text { Duty cyde }\end{array}$ & $\begin{array}{c}\text { Experimental plan - Step 1 } \\
\text { Extraction time } \\
\text { Extract }\end{array}(\%)$ & $\begin{array}{c}\text { Amplitude level } \\
(\%)\end{array}$ & Sample/solvent ratio \\
\hline CA01 & 20 & 5 & 30 & $1: 60$ \\
CA02 & 20 & 5 & 50 & $1: 40$ \\
CA03 & 80 & 5 & 30 & $1: 40$ \\
CA04 & 80 & 5 & 50 & $1: 60$ \\
CA05 & 20 & 15 & 30 & $1: 40$ \\
CA06 & 20 & 15 & 50 & $1: 60$ \\
CA07 & 80 & 15 & 30 & $1: 60$ \\
CA08 & 80 & 15 & 50 & $1: 40$ \\
CA09 & 50 & 10 & 40 & $1: 50$ \\
CA10 & 50 & 10 & 40 & $1: 50$ \\
CA11 & 50 & 10 & 40 & $1: 50$ \\
\hline
\end{tabular}

\begin{tabular}{ccccc} 
B & \multicolumn{5}{c}{$\begin{array}{c}\text { Experimental plan - Step 2 } \\
\text { Duty cyde } \\
(\%)\end{array}$} & $\begin{array}{c}\text { Extraction time } \\
\text { (min) }\end{array}$ & $\begin{array}{c}\text { Amplitude level } \\
(\%)\end{array}$ & Sample/solvent ratio \\
Extract & $(\%)$ & 15 & 50 & $1: 40$ \\
\hline CA08 & 80 & 15 & 50 & $1: 20$ \\
CA_R20 & 80 & 15 & 50 & $1: 15$ \\
CA_R15 & 80 & 15 & 50 & $1: 10$ \\
CA_R10 & 80 & 15 &
\end{tabular}
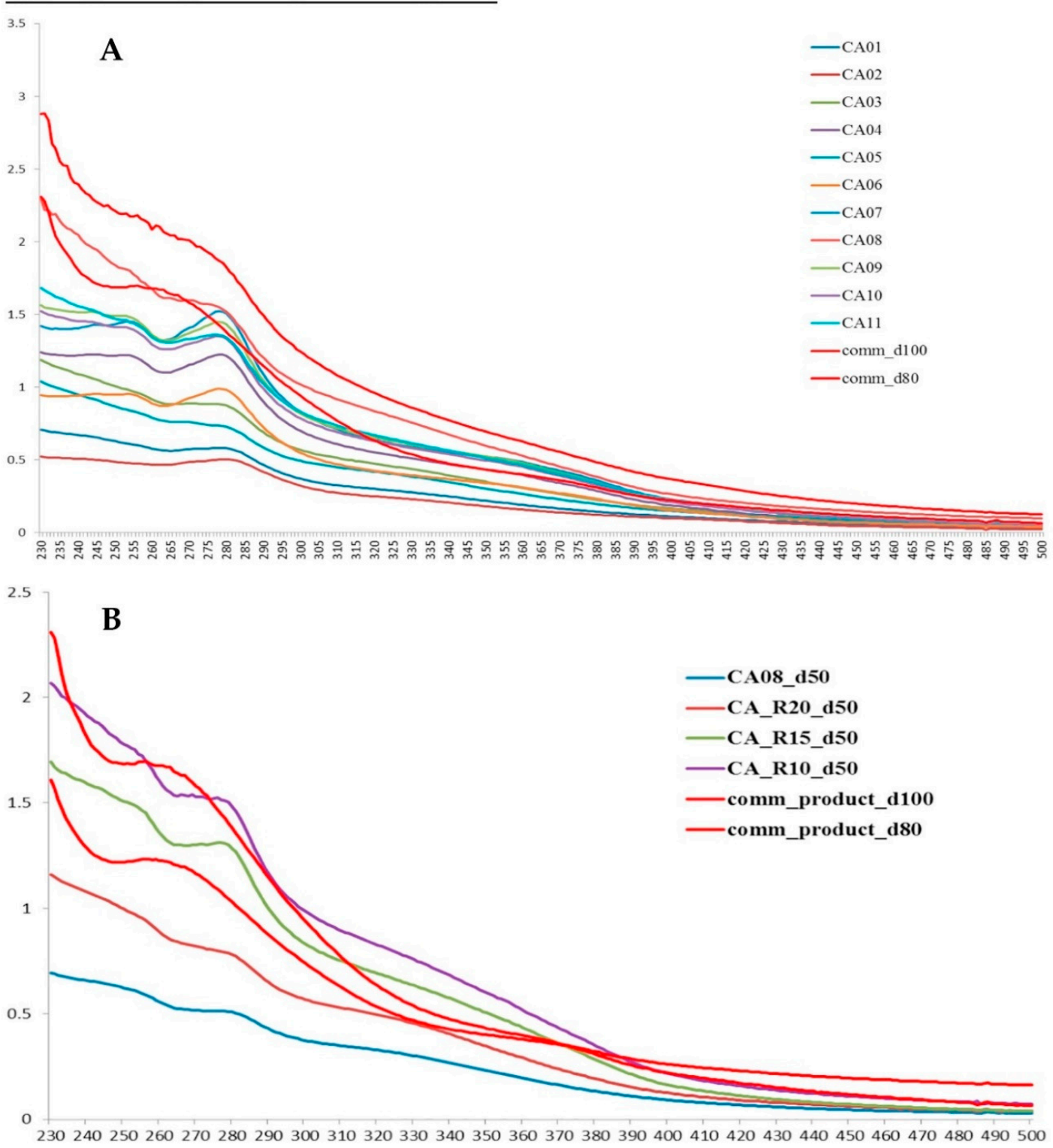

Figure 2. (A) Step 1 experimental conditions and relative UV-Vis spectra (recorded at 230-500 nm) of the eleven PUAE extracts and Castanea spp. commercial products diluted 1:80 (comm_d80) and 1:100 (comm_1:100). (B) Step 2 experimental conditions and relative UV-Vis spectra (recorded at 230-500 nm) of the PUAE extracts (CA_R20,CA_R15,CA_R10), carried out optimizing the sample/solvent ratio, together with CA08, comm_d80, and comm_d100 spectra. 
Amplitude is very important in the extraction intensification [2]; indeed, if the amplitude is increased, the compression and rarefaction cycles of ultrasonic waves also increase and there is a higher recovery of the phyto-compounds, as shown in this research (the CA08 extract was obtained by the maximum amplitude). During the PUAE process the solutes are in contact with the extraction solvent and the extraction efficiency is mainly influenced by the interaction time composed by two different phases (e.g., dissolution of the soluble substances on the matrix surfaces and the solute mass transfer from the matrix into the solvent by diffusion) [22]. In this case, the best extraction time was 15 min. In other similar studies [2,23], the sample/solvent ratio was identified as the most discriminating variable to build a good model for extraction from plant material; moreover, the solute/solvent ratio is one of the most important factors during mass transfer, since a larger volume of solvent allows to accelerate the diffusion process, but using too high solvent amounts could cause a saturation of the liquid in the extraction system. In general, an increase in the concentration of bioactive substances is observed if the solute/solvent ratio increases [22]. For this reason, in this study, further extraction experiments (step 2) were performed setting this variable to 1/20,1/15 and 1/10 (CA_R20,CA_R15, CA_R10, respectively) to save more extraction solvent and improve the extraction yield, as reported in previous studies $[11,24]$. The new extracts were spectrophotometrically compared to CA08 extract and commercial bud-derivatives at the same dilution (1:50). Figure 2B shows that the CA_R10 extract (duty cycle of $80 \%$, extraction time of $15 \mathrm{~min}$, amplitude level of $50 \%$, and a solvent/ratio of 1/10) was the most promising extraction condition because it was the most similar to the commercial products (comm_d80 and comm_d100). The selected PUAE extract (CA_R10) was then compared to Geal Pharma commercial bud-derivatives to evaluate the phytochemical composition and the extraction recovering percentage by HPLC.

\subsection{Phytochemical Fingerprint and Recovering Percentage for PUAE Extraction}

Today many scientific reports on analytical strategies describe HPLC as the best characterization tool in the botanical analysis $[25,26]$. This research showed preliminary phytochemical profiles of traditional bud-preparations and PUAE extracts, obtained by HPLC/DAD analyses, to compare bud-derivatives obtained by maceration and extracts obtained by PUAE. Figure 3a reported phenolic profiles of traditional chestnut bud-derivatives and innovative PUAE extracts.

These specific fingerprints were used to assess the contribution of each bioactive class to the relative phytocomplex. Molecule identification and characterization were carried out by comparing UV-visible absorption spectra and chromatographic retention times [23]. 23 molecules were selected and characterized as fingerprint biomarkers thanks to their proved health-effective capacities on humans (Supplementary Table S2).

The approach utilized in this study was based on a reliable, sensitive, and simple protocol that may be also utilized for the quality control and assessment of other natural products and related eco-sustainable extracts as shown in other studies $[16,23]$. Selected substances were grouped into different bioactive classes both for processing waste extracts and traditional bud-preparations to compare their amounts (expressed as $\mathrm{mg} / 100 \mathrm{~g}$ FW) as reported in previous studies [2,27]. Sustainable technologies for ultrasound extraction rapidly extracted a phytochemical amount of $160.42 \mathrm{mg} / 100 \mathrm{~g}$ FW, that may be considered an excellent amount if compared to the compound content of the related original commercial bud-extracts ( $1276.17 \mathrm{mg} / 100 \mathrm{~g}$ FW). In particular, PUAE allowed extracting a good content of tannins (about $40 \%$ of total phenolics), phenolic acids (about 30\%), and flavonols (about $24 \%$ ), while traditional maceration mainly extracted tannins (about $65 \%$ of total phenolics) and phenolic acids (about 22\%), as shown in Figure 3b. Ultrasound extraction also extracted high contents of organic acids $(73.06 \pm 0.27 \mathrm{mg} / 100 \mathrm{~g} \mathrm{FW})$, even if much lower than traditional maceration $(516.51 \pm 0.13 \mathrm{mg} / 100 \mathrm{~g} \mathrm{FW})$.

Tannins $(481.22 \pm 2.04 \mathrm{mg} / 100 \mathrm{~g}$ FW for traditional preparations and $30.27 \pm 1.27 \mathrm{mg} / 100 \mathrm{~g}$ FW for PUAE extracts) were the main polyphenolic class in the analyzed products derived from chestnut buds, followed by cinnamic acids (in particular, chlorogenic acids presented values of $14.23 \pm 0.29 \mathrm{mg} / 100 \mathrm{~g}$ 
FW for traditional preparations and $11.10 \pm 0.06 \mathrm{mg} / 100 \mathrm{~g}$ FW for PUAE extracts) and benzoic acids. Quercetin was also identified in good amounts $(30.64 \pm 0.23 \mathrm{mg} / 100 \mathrm{~g}$ FW for traditional preparations and $15.39 \pm 0.22 \mathrm{mg} / 100 \mathrm{~g}$ FW for PUAE extracts) as reported in similar studies $[7,28]$. The analyzed extracts also presented discrete contents of vitamin C $(18.08 \pm 0.06 \mathrm{mg} / 100 \mathrm{~g}$ FW for traditional preparations and $11.71 \pm 0.16 \mathrm{mg} / 100 \mathrm{~g}$ FW for PUAE extracts). Data on the recovering percentage for each marker are reported in Table 1.

Table 1. The recovering percentage for each biologically active molecule selected as a health-promoting marker in PUAE extracts in relation to the original bud-derivative composition.

\begin{tabular}{|c|c|c|}
\hline Class & Molecule & Recovering Percentage (\%) \\
\hline \multirow{4}{*}{ Cinnamic acids } & caffeic acid & $92 \%$ \\
\hline & chlorogenic acid & $78 \%$ \\
\hline & coumaric acid & / \\
\hline & ferulic acid & $45 \%$ \\
\hline \multirow{5}{*}{ Flavonols } & hyperoside & $39 \%$ \\
\hline & isoquercitrin & / \\
\hline & quercetin & $50 \%$ \\
\hline & quercitrin & $4 \%$ \\
\hline & rutin & $19 \%$ \\
\hline \multirow{2}{*}{ Benzoic acids } & ellagic acid & $12 \%$ \\
\hline & gallic acid & $2 \%$ \\
\hline \multirow{2}{*}{ Catechins } & catechin & $31 \%$ \\
\hline & epicatechin & $13 \%$ \\
\hline \multirow{2}{*}{ Tannins } & castalagin & $7 \%$ \\
\hline & vescalagin & $4 \%$ \\
\hline \multirow{6}{*}{ Organic acids } & citric acid & $5 \%$ \\
\hline & malic acid & $5 \%$ \\
\hline & oxalic acid & $33 \%$ \\
\hline & quinic acid & $19 \%$ \\
\hline & succinic acid & $9 \%$ \\
\hline & tartaric acid & $30 \%$ \\
\hline \multirow{2}{*}{ Vitamin C } & ascorbic acid & $66 \%$ \\
\hline & dehydroascorbic acid & $53 \%$ \\
\hline
\end{tabular}

The recovering percentage was calculated starting from the amounts (A) (mean values were used, $\mathrm{N}=3$ ) of each bioactive molecule detected in the traditional bud-preparation (TBP) and innovative PUAE extracts (IPE) as follow: $1-\left[\left(\mathrm{A}_{\mathrm{TBP}}-\mathrm{A}_{\mathrm{IPE}}\right) / \mathrm{A}_{\mathrm{TBP}}\right]$.

In Figure 4 the total amounts (in $\mathrm{mg} / 100 \mathrm{~g}$ FW) of bioactive classes in the PUAE extract and the commercial bud-preparations are reported. Phenolic classes, as flavonols and cinnamic acids, and vitamin $C$ represent the most preserved classes of health-promoting substances in the processing waste extracts after PUAE application. 
Traditional bud-derivative

a. Cinnamic acids and flavonols

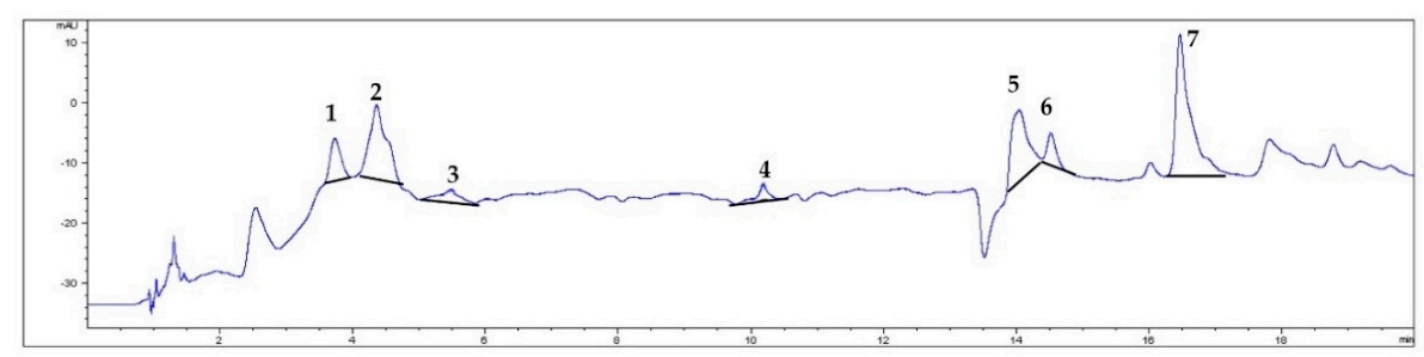

b. Benzoic acids, catechins, and tannins

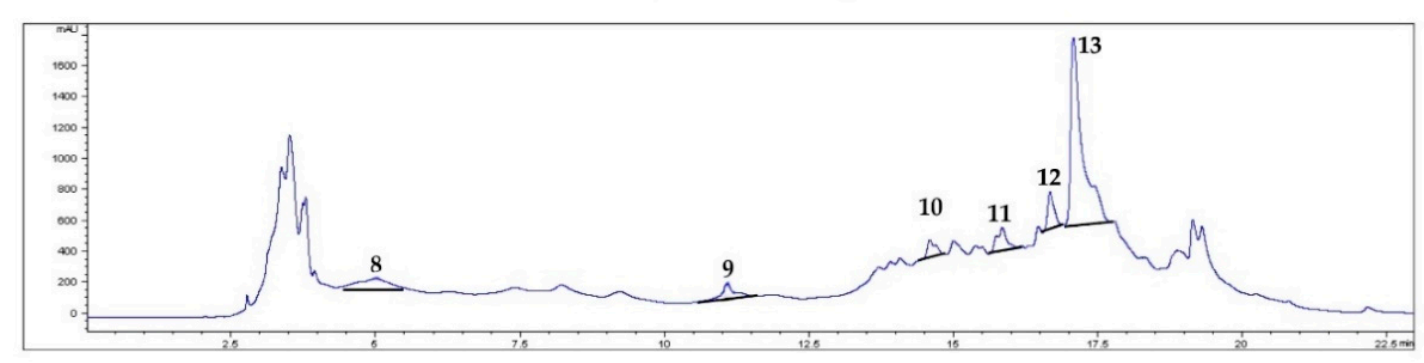

Innovative PUAE extracts

c. Cinnamic acids and flavonols

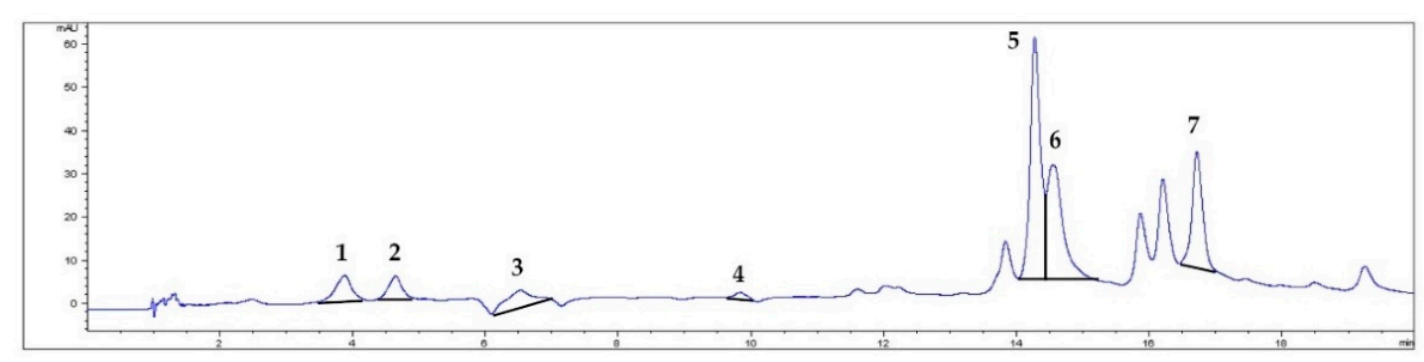

d. Benzoic acids, catechins, and tannins

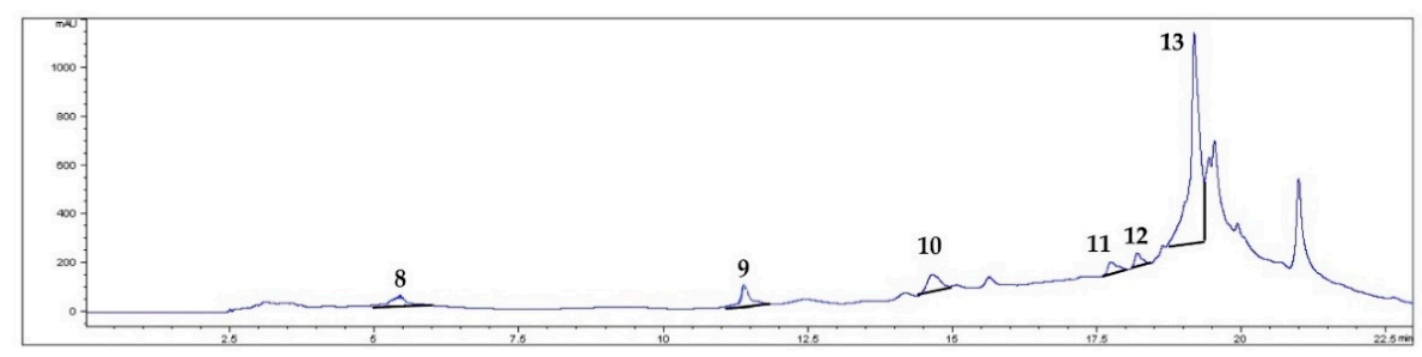

(a)

Figure 3. Cont. 


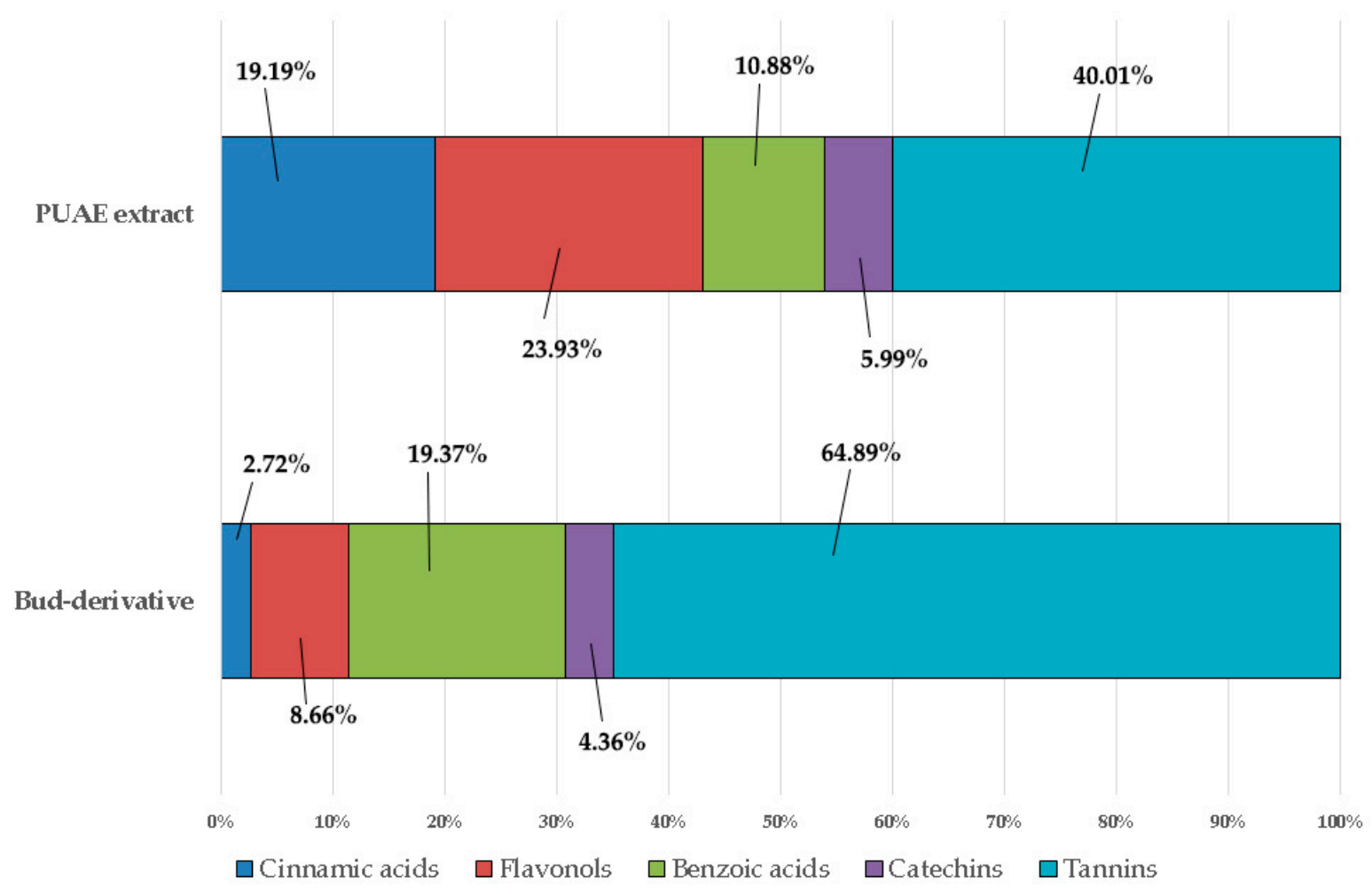

(b)

Figure 3. (a) The chromatographic pattern of phenolics detected in the analyzed extracts. Chlorogenic acid $=1$; caffeic acid $=2$; ferulic acid $=3$; hyperoside $=4$; rutin $=5$; quercitrin $=6$; quercetin $=7$; gallic acid $=8$; catechin $=9$; epicatechin $=10 ;$ castalagin $=11$; vescalagin $=12 ;$ ellagic acid $=13$. (b) Percentage contribution of phenolic classes to total polyphenols. Cinnamic acids (ferulic acid, coumaric acid, chlorogenic acid, caffeic acid), flavonols (rutin, quercitrin, quercetin, isoquercitrin, hyperoside), catechins (epicatechin, catechin), and tannins (vescalagin, castalagin) were considered as health-promoting markers.

These compounds are very relevant for human health and nutrition thanks to their biological properties, as antihepatotoxic, anti-atherosclerotic, antioxidant, anticancer, anti-HIV replication, and anti-inflammatory activities [29]. In particular, the health-positive effects of polyphenols and vitamin $\mathrm{C}$ are mainly related to their anti-inflammatory activities and antioxidant capacities [30]. Moreover, several studies have demonstrated that phenolics may be involved in the cellular signaling flow, first controlling the biological actions of the transcription factors and then influencing the expression of specific genes that are involved in cellular survival and metabolism [31]. Specifically, in vitro anticancer activity of plant material and derived-products as bud-preparations (e.g., activity against breast, colon, lung, and liver cancer) may depend on the main polyphenolic compounds, as chlorogenic acid and other cinnamic acids, and flavonols, as recently reported by Li et al. [32]. The present study showed a chromatographic bioactive pattern similar to other studies $[13,33]$. Synergistic and additive effects of the several bioactive substances are very important for the healthy value of herbal preparation, but HPLC-DAD does generally not allow to detect all the biologically active or nutritional molecules included in the considered phytocomplex because of the high number of potential bioactive substances [34]. For this reason, the addition of more biomarkers in the described HPLC analysis may be considered very important for further studies, because it could be a further step toward the complete identification of the active molecules involved in the complex composition of a herbal product [3]. 


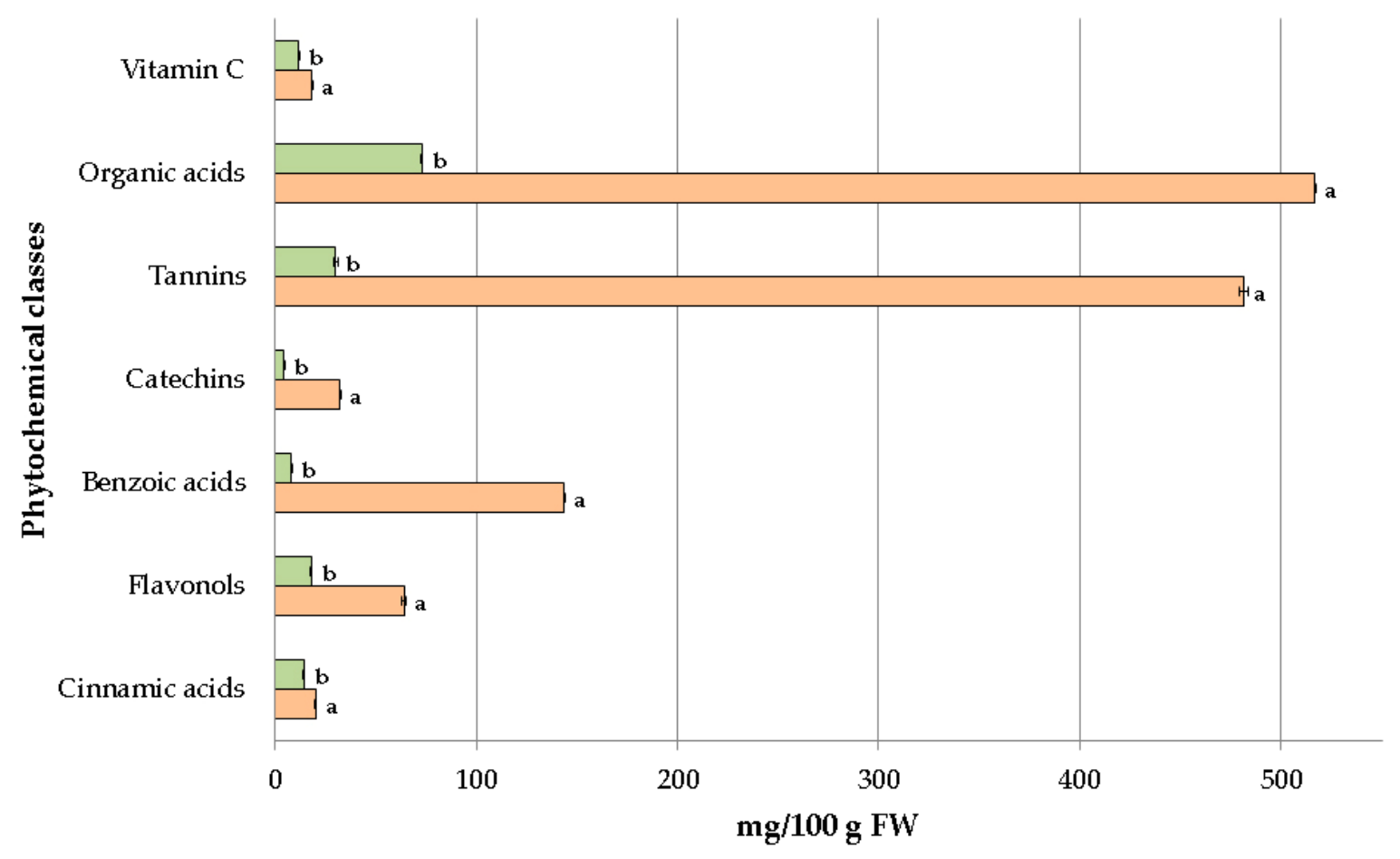

$\square$ PUAE extract $\square$ bud-derivative

Figure 4. Amounts of phytochemical classes of chestnut commercial and PUAE extracts. Results are reported as $\mathrm{mg} / 100 \mathrm{~g}$ of fresh weight $(\mathrm{FW})$ of buds/marcs. Mean values \pm standard deviation bars are reported in the histogram. Significant statistical differences $(p<0.05)$ are highlighted by different letters (e.g., a, b).

A percentage to compare phytochemical contents in the traditional bud-preparations and PUAE extracts have been calculated for each phytochemical class. The $12.6 \%$ of the chestnut bud-preparation content was maintained in the processing waste bud-extracts and it may be recovered to be used in other herbal products or food supplements. This recovery percentage is similar to values obtained in previous studies [22,35-37]. Figure 5 showed the recovering percentage for all the identified classes of biologically active molecules in PUAE extracts related to the corresponding commercial preparations produced by traditional maceration. In this study, cinnamic acids (in particular, caffeic, and chlorogenic acids) and vitamin $C$ represent the most preserved classes in the PUAE extracts if compared to the correspondent Castanea spp. bud-preparations with percentage values of about $70 \%$ and $65 \%$, respectively, as already reported in previous studies $[13,38]$. The other classes, as organic and benzoic acids, tannins, flavonols, and catechins were also characterized in the processing waste extracts, but they presented lower values (about 5-30\%) than the corresponding commercial preparations (Figure 5) as reported in similar studies [21,39].

The recovery of phytochemicals, in particular polyphenols, from plant sources has been usually carried out by conventional extraction techniques (e.g., maceration, Soxhlet extractor, and stirring). These techniques require energy consumption, high organic solvent, and long times, and provide extracts with limited yields in relation to the time extraction. This study showed that Pulsed Ultrasound-Assisted Extraction (UAE) may be considered an efficient, effective, and rapid technology to recover phenolics from processing waste with high extraction yields $(5-20 \%)$ as already reported in several studies $[10,22,35]$. 


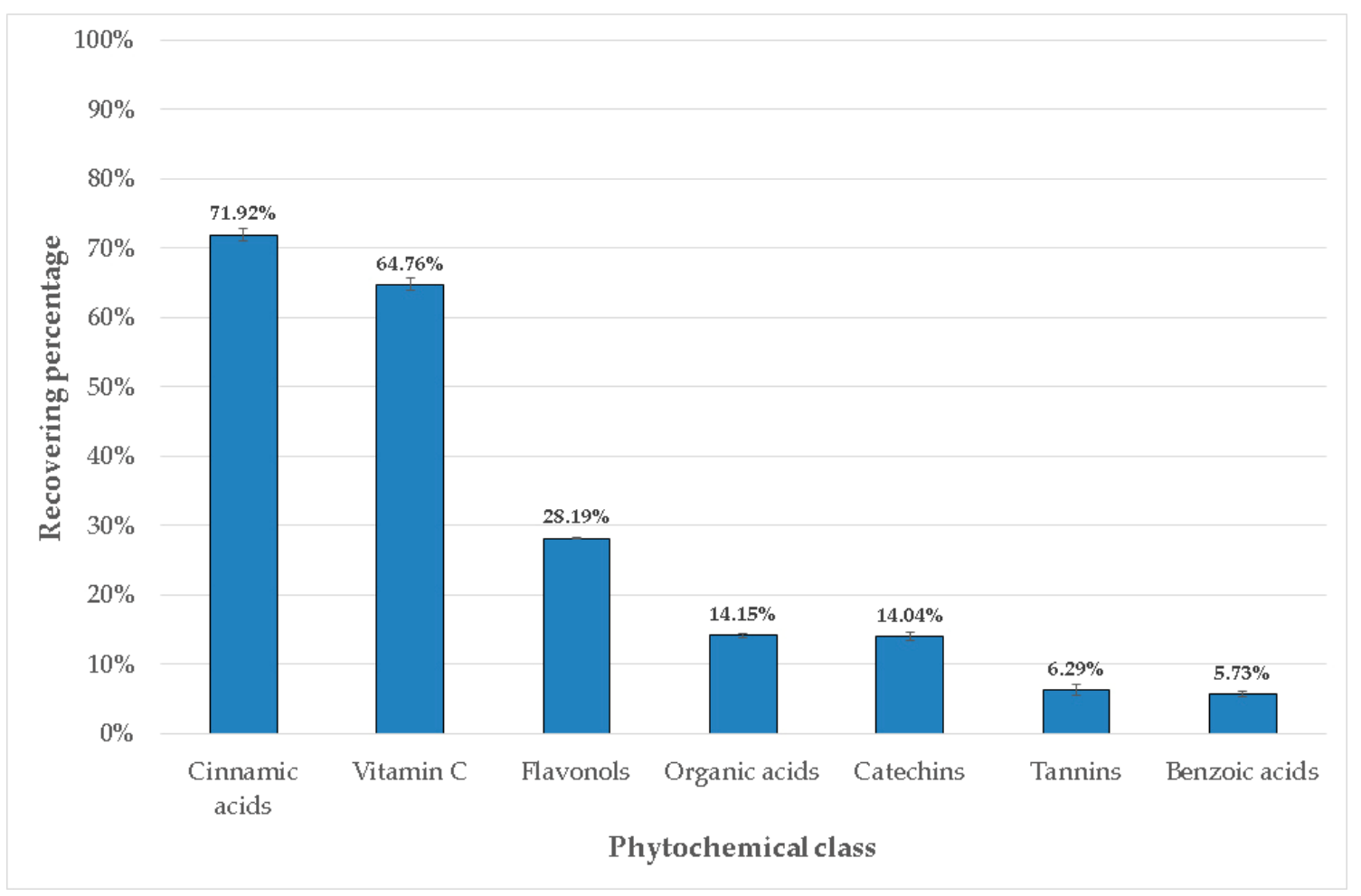

Figure 5. The recovering percentage for the class of biologically active molecules in PUAE extracts.

\section{Conclusions}

In this research, a sustainable approach for the re-use of the herbal preparation by-products was developed as an alternative to common procedures (e.g., composting or incineration), to develop potential high added-value innovative products for the food supplement and herbal product market, that may present an important economic impact for the food supplement industries and commercial producers, representing a significant innovation in the sector of natural products. Indeed, this study showed that the bud-derivative by-products may be further used as an important source of bioactive compounds to be utilized in other commercial products (e.g., cosmetics).

This study highlighted that extracts obtained from an ultrasound extraction of chestnut bud-preparation processing waste showed good amounts of biologically active molecules, with a chemical profile similar to the chromatographic pattern of the original bud-preparation obtained by a traditional maceration. In the ultrasound extracts derived from processing waste, several bioactive compounds were identified and quantified in good amounts (about $15 \%$ in comparison to the original bud-preparations). This percentage is very good considering that the molecules were extracted from processing waste that otherwise should be eliminated by no sustainable processes (incineration or composting). Moreover, the ultrasonic-assisted extraction shows extremely reduced extraction times compared to the traditional maceration. For this reason, this ecological extraction technique (PUAE) may also be favorably considered as an excellent and sustainable alternative to processing waste management based on the traditional systems, such as composting or incineration.

This protocol developed for Castanea spp. buds may be also applied to other species commonly utilized in phytotherapeutic industries as a good and innovative tool to manage processing waste deriving from herbal preparation productions.

Supplementary Materials: The following are available online at http://www.mdpi.com/2071-1050/12/24/10640/s1, Table S1: Chromatographic conditions of the used HPLC methods. Table S2: HPLC-fingerprint of the chestnut bud-preparations and corresponding PUAE extracts obtained by from the processing waste. 
Author Contributions: Conceptualization, D.D., F.T., G.L.B. and R.B.; methodology, D.D. and F.T.; validation, D.D., and F.T.; formal analysis, D.D., F.T., G.G., and I.R.; investigation, D.D. and F.T.; resources, M.G.; data curation, D.D., M.G.M., and F.T.; writing-original draft preparation, D.D. and F.T.; writing-review and editing, D.D., F.T. G.L.B., and R.B.; supervision, G.L.B. and R.B.; project administration, G.L.B. and R.B.; funding acquisition, G.L.B. and R.B. All authors have read and agreed to the published version of the manuscript.

Funding: This research was funded by FINNOVER project (Strategie Innovative per lo Sviluppo di Filiere Verdi Transfrontaliere) - Interreg Alcotra Italy-France European cross-border program 2014-2020, grant number 1198.

Acknowledgments: The authors thank the commercial company GEAL Pharma (Bricherasio, Torino, Italy) for providing plant material.

Conflicts of Interest: The authors declare no conflict of interest.

\section{References}

1. Lin, C.S.K.; Pfaltzgraff, L.A.; Herrero-Davila, L.; Mubofu, E.B.; Abderrahim, S.; Clark, J.H.; Koutinas, A.; Kopsahelis, N.; Stamatelatou, K.; Dickson, F.; et al. Food waste as a valuable resource for the production of chemicals, materials and fuels. Current situation and global perspective. Energy Environ. Sci. 2012, 6, 426-464. [CrossRef]

2. Turrini, F.; Donno, D.; Beccaro, G.L.; Zunin, P.; Pittaluga, A.; Boggia, R. Pulsed Ultrasound-Assisted Extraction as an Alternative Method to Conventional Maceration for the Extraction of the Polyphenolic Fraction of Ribes nigrum Buds: A New Category of Food Supplements Proposed by The FINNOVER Project. Foods 2019, 8, 466. [CrossRef] [PubMed]

3. Donno, D.; Beccaro, G.; Cerutti, A.; Mellano, M.G.; Bounous, M.M.A.G. Bud Extracts as New Phytochemical Source for Herbal Preparations-Quality Control and Standardization by Analytical Fingerprint. In Phytochemicals_Isolation, Characterisation and Role in Human Health; Rao, A.V., Rao, L.G., Eds.; InTech: Rijeka, Croazia, 2015; Volume 1, pp. 187-218.

4. Donno, D.; Beccaro, G.L.; Carlen, C.; Ançay, A.; Cerutti, A.K.; Mellano, M.G.; Bounous, G. Analytical fingerprint and chemometrics as phytochemical composition control tools in food supplement analysis: characterization of raspberry bud preparations of different cultivars. J. Sci. Food Agric. 2015, 96, 3157-3168. [CrossRef] [PubMed]

5. Shrishrimal, N.; Das, D. Retraction Notice: Phytochemicals from Plants to Combat Cardiovascular Disease. Curr. Med. Chem. 2012, 19, 2242-2251. [CrossRef]

6. Nicoletti, M. Nutraceuticals and botanicals: Overview and perspectives. Int. J. Food Sci. Nutr. 2012, 63, 2-6. [CrossRef] [PubMed]

7. Donno, D.; Beccaro, G.L.; Mellano, M.G.; Bonvegna, L.; Bounous, G. Castaneaspp. buds as a phytochemical source for herbal preparations: Botanical fingerprint for nutraceutical identification and functional food standardisation. J. Sci. Food Agric. 2014, 94, 2863-2873. [CrossRef]

8. Boggia, R.; Turrini, F.; Anselmo, M.; Zunin, P.; Donno, D.; Beccaro, G.L. Feasibility of UV-VIS-Fluorescence spectroscopy combined with pattern recognition techniques to authenticate a new category of plant food supplements. J. Food Sci. Technol. 2017, 54, 2422-2432. [CrossRef]

9. Chemat, F.; Vian, M.A.; Cravotto, G. Green Extraction of Natural Products: Concept and Principles. Int. J. Mol. Sci. 2012, 13, 8615-8627. [CrossRef]

10. Putnik, P.; Lorenzo, J.; Barba, F.J.; Roohinejad, S.; Jambrak, A.R.; Granato, D.; Montesano, D.; Kovačević, D.B. Novel Food Processing and Extraction Technologies of High-Added Value Compounds from Plant Materials. Foods 2018, 7, 106. [CrossRef]

11. Turrini, F.; Zunin, P.; Catena, S.; Villa, C.; Alfei, S.; Boggia, R. Traditional or hydro-diffusion and gravity microwave coupled with ultrasound as green technologies for the valorization of pomegranate external peels. Food Bioprod. Process. 2019, 117, 30-37. [CrossRef]

12. Chemat, F.; Rombaut, N.; Sicaire, A.-G.; Meullemiestre, A.; Fabiano-Tixier, A.-S.; Abert-Vian, M. Ultrasound assisted extraction of food and natural products. Mechanisms, techniques, combinations, protocols and applications. A review. Ultrason. Sonochem. 2017, 34, 540-560. [CrossRef] [PubMed]

13. Turrini, F.; Donno, D.; Boggia, R.; Beccaro, G.L.; Zunin, P.; Leardi, R.; Pittaluga, A.M. An innovative green extraction and re-use strategy to valorize food supplement by-products: Castanea sativa bud preparations as case study. Food Res. Int. 2019, 115, 276-282. [CrossRef] [PubMed] 
14. Ordre National des Pharmaciens. Pharmacopée Française, Codex Medicamentarius Gallicus, Codex Français: Monographie, Préparations Homéopathiques, 8th ed.; Ministère de la Santé Publique et de la Population: Paris, France, 1965.

15. Santos, H.M.; Lodeiro, C.; Capelo-Martnez, J.-L. The Power of Ultrasound. In Ultrasound in Chemistry: Analytical Applications; Wiley Online Library: Hoboken, NJ, USA, 2009; pp. 1-16.

16. Donno, D.; Boggia, R.; Zunin, P.; Cerutti, A.K.; Guido, M.; Mellano, M.G.; Prgomet, Z.; Beccaro, G.L. Phytochemical fingerprint and chemometrics for natural food preparation pattern recognition: an innovative technique in food supplement quality control. J. Food Sci. Technol. 2016, 53, 1071-1083. [CrossRef] [PubMed]

17. Mok, D.K.; Chau, F.-T. Chemical information of Chinese medicines: A challenge to chemist. Chemom. Intell. Lab. Syst. 2006, 82, 210-217. [CrossRef]

18. Cuadros-Rodríguez, L.; Ruiz-Samblás, C.; Valverde-Som, L.; Pérez-Castaño, E.; González-Casado, A. Chromatographic fingerprinting: An innovative approach for food 'identitation' and food authentication-A tutorial. Anal. Chim. Acta 2016, 909, 9-23. [CrossRef]

19. Liu, M.; Liu, S.; Shi, X.; Liu, M.; Zhang, Y.D.L.; Wang, Q. Quality Evaluation of a Herbal Prescription Through Quantification of 40 Components by HPLC-ESI-MS/MS. Phytochem. Anal. 2011, 23, 365-372. [CrossRef] [PubMed]

20. Shi, Z.-Q.; Song, D.-F.; Li, R.-Q.; Yang, H.; Qi, L.-W.; Xin, G.-Z.; Wang, D.-Q.; Song, H.-P.; Chen, J.; Hao, H.; et al. Identification of effective combinatorial markers for quality standardization of herbal medicines. J. Chromatogr. A 2014, 1345, 78-85. [CrossRef]

21. Grassino, A.N.; Ostojić, J.; Miletić, V.; Djaković, S.; Bosiljkov, T.; Zorić, Z.; Ježek, D.; Brnčić, S.R.; Brnčić, M. Application of high hydrostatic pressure and ultrasound-assisted extractions as a novel approach for pectin and polyphenols recovery from tomato peel waste. Innov. Food Sci. Emerg. Technol. 2020, 64, 102424. [CrossRef]

22. Pacheco, N.; Ayora-Talavera, T.; Espinosa-Andrews, H.; Sánchez-Contreras, A.; Pacheco, N. Ultrasound Assisted Extraction for the Recovery of Phenolic Compounds from Vegetable Sources. Agronomy 2017, 7, 47. [CrossRef]

23. Turrini, F.; Donno, D.; Beccaro, G.L.; Pittaluga, A.; Grilli, M.; Zunin, P.; Boggia, R. Bud-Derivatives, a Novel Source of Polyphenols and How Different Extraction Processes Affect Their Composition. Foods 2020, 9, 1343. [CrossRef]

24. Turrini, F.; Boggia, R.; Donno, D.; Parodi, B.; Beccaro, G.; Baldassari, S.; Signorello, M.G.; Catena, S.; Alfei, S.; Zunin, P. From pomegranate marcs to a potential bioactive ingredient: A recycling proposal for pomegranate-squeezed marcs. Eur. Food Res. Technol. 2020, 246, 273-285. [CrossRef]

25. Hakimzadeh, N.; Parastar, H.; Fattahi, M. Combination of multivariate curve resolution and multivariate classification techniques for comprehensive high-performance liquid chromatography-diode array absorbance detection fingerprints analysis of Salvia reuterana extracts. J. Chromatogr. A 2014, 1326, 63-72. [CrossRef]

26. Nunes, M.A.; Rodrigues, F.; Alves, R.C.; Oliveira, M.B.P.P. Herbal products containing Hibiscus sabdariffa L., Crataegus spp., and Panax spp.: Labeling and safety concerns. Food Res. Int. 2017, 100, 529-540. [CrossRef] [PubMed]

27. Turrini, F.; Vallarino, G.; Cisani, F.; Donno, D.; Beccaro, G.L.; Zunin, P.; Boggia, R.; Pittaluga, A.; Grilli, M. Use of an Animal Model to Evaluate Anxiolytic Effects of Dietary Supplementation with Tilia tomentosa Moench Bud Extracts. Nutrients 2020, 12, 3328. [CrossRef] [PubMed]

28. Donno, D.; Cerutti, A.K. Fitoterapia e castagno: I gemmoderivati. CASTANEA 2014, 1, 10-11.

29. Beccaro, G.L.; Donno, D.; Lione, G.G.; De Biaggi, M.; Gamba, G.; Rapalino, S.; Riondato, I.; Gonthier, P.; Mellano, M.G. Castanea spp. Agrobiodiversity Conservation: Genotype Influence on Chemical and Sensorial Traits of Cultivars Grown on the Same Clonal Rootstock. Foods 2020, 9, 1062. [CrossRef] [PubMed]

30. Gamba, G.; Donno, D.; Mellano, M.G.; Riondato, I.; De Biaggi, M.; Randriamampionona, D.; Beccaro, G.L. Phytochemical Characterization and Bioactivity Evaluation of Autumn Olive (Elaeagnus umbellata Thunb.) Pseudodrupes as Potential Sources of Health-Promoting Compounds. Appl. Sci. 2020, 10, 4354. [CrossRef]

31. De Biaggi, M.; Donno, D.; Mellano, M.G.; Gamba, G.; Riondato, I.; Rakotoniaina, E.N.; Beccaro, G.L. Emerging species with nutraceutical properties: Bioactive compounds from Hovenia dulcis pseudofruits. Food Chem. 2020, 310, 125816. [CrossRef] [PubMed] 
32. Li, S.; Li, S.-K.; Gan, R.-Y.; Song, F.-L.; Kuang, L.; Li, H.-B. Antioxidant capacities and total phenolic contents of infusions from 223 medicinal plants. Ind. Crop. Prod. 2013, 51, 289-298. [CrossRef]

33. Donno, D.; Beccaro, G.; Masnari, F.; Mellano, G.; Cerutti, A.K.; Bounous, G. Castanea spp. as phytochemical source for herbal preparations. Acta Hortic. 2014, 75-82. [CrossRef]

34. Donno, D.; Mellano, M.G.; Riondato, I.; De Biaggi, M.; Andriamaniraka, H.; Gamba, G.; Beccaro, G.L. Traditional and Unconventional Dried Fruit Snacks as a Source of Health-Promoting Compounds. Antioxidants 2019, 8, 396. [CrossRef] [PubMed]

35. Machado, A.P.D.F.; Pereira, A.L.D.; Barbero, G.F.; Martínez, L. Recovery of anthocyanins from residues of Rubus fruticosus, Vaccinium myrtillus and Eugenia brasiliensis by ultrasound assisted extraction, pressurized liquid extraction and their combination. Food Chem. 2017, 231, 1-10. [CrossRef] [PubMed]

36. Chuyen, H.V.; Nguyen, M.H.; Roach, P.D.; Golding, J.B.; Parks, S.E. Microwave-assisted extraction and ultrasound-assisted extraction for recovering carotenoids from $\mathrm{Gac}$ peel and their effects on antioxidant capacity of the extracts. Food Sci. Nutr. 2018, 6, 189-196. [CrossRef] [PubMed]

37. Dahmoune, F.; Boulekbache-Makhlouf, L.; Moussi, K.; Aoun, O.; Spigno, G.; Madani, K. Valorization of Citrus limon residues for the recovery of antioxidants: Evaluation and optimization of microwave and ultrasound application to solvent extraction. Ind. Crop. Prod. 2013, 50, 77-87. [CrossRef]

38. Donno, D.; Turrini, F.; Boggia, R.; Guido, M.; Mellano, M.G.; Beccaro, G.L. Phytochemicals from Castanea spp. Buds and green extraction technologies: The finnover project. Italus Hortus 2020, 27, 19-29.

39. Samaram, S.; Mirhosseini, H.; Tan, C.P.; Ghazali, H.M. Ultrasound-Assisted Extraction (UAE) and Solvent Extraction of Papaya Seed Oil: Yield, Fatty Acid Composition and Triacylglycerol Profile. Molecules 2013, 18, 12474-12487. [CrossRef]

Publisher's Note: MDPI stays neutral with regard to jurisdictional claims in published maps and institutional affiliations. 